\title{
BJMHR
}

British Journal of Medical and Health Research

Journal home page: www.bjmhr.com

\section{A cross-sectional study of Evaluation of Malocclusion in Children Aged 8-12 years in the Village of Zakigonj, Sylhet district, Bangladesh}

Faria Tabassum Tanni ${ }^{\mathbf{1}}$, ${ }^{*}$ Sonia Jahan Bithi ${ }^{\mathbf{2}}$,Helal uddin ${ }^{\mathbf{3}}$, Nazia Mehanaz ${ }^{\mathbf{4}}$ 1.Senior Consultant Orthodontics,Taqwa specialized Hospital \&Dental Care,Dhaka

2. Department of Prosthodontics, Mandy Dental College \& Hospital, Dhaka 3. Department of Orthodontics, Bangabandhu Sheikh Mujib Medical University, Shahbag, Dhaka

4. Department of Pedodontics, Bangabandhu Sheikh Mujib Medical University, Shahbag, Dhaka

\section{ABSTRACT}

Malocclusion is defined as an irregularity of the teeth or a mal relationship between the dental arches beyond the range of what is accepted as normal. It has large impact on individual and society in terms of discomfort, quality of life and social and functional limitations. The etiology of malocclusion may be genetic, environmental or more commonly a combination of them. To determine the prevalence of malocclusion in children aged 8-12 years in the village of Zakigonj, Sylhet district A cross sectional descriptive survey was conducted among rural area (374) school- age children of Sylhet Zakigonj Upazila in Bangladesh. A total of 374 children aged 08-12 year old was examined for Class I, Class II, Class III molar relationship, increased over jet, increased over bite, open bite, crowding, cross bite and spacing after obtaining the written consent from the students, legal guardians and school authorities. The majority $173(70.0 \%)$ patients were found malocclusion in age <10 years and $89(70.1 \%)$ in age >10 years. Majority $121(69.9 \%)$ participants were found Angle's class $\mathrm{I}$ in age $<10$ years and $75(84.3 \%)$ in age $>10$ years. One hundred six $(61.3 \%)$ patients were found crowding of malocclusion in age $<10$ years and 67(75.3\%) in age $>10$ years group. Which were not statistically significant $(\mathrm{p}<0.05)$ but increased overjet, open bite, cross bite and spacing were not statistically significant ( $>>0.05)$ between two groups. The results suggested that there is increased prevalence of malocclusion among children in the 8-12 years age group. The observation of this study will provide baseline data for implement early interceptive treatment for the elimination of factors inhibiting dental arch development as well as skeletal jaw growth.

Keywords: Malocclusion, Village, genetic, environmental 


\section{INTRODUCTION}

Malocclusion is defined as an irregularity of the teeth or a malrelationship between the dental arches beyond the range of what is accepted as normal. It is a multifactorial oral condition caused by general factors such as heredity, congenital defects, nutritional deficiencies and abnormal pressure habits. Malocclusion can also occur due to factors located in the dental arch such as anomalies of tooth size, shape, supernumerary teeth, dental caries and premature loss of primary teeth. ${ }^{1}$

It has large impact on individual and society in terms of discomfort, quality of life and social and functional limitations. The etiology of malocclusion may be genetic, environmental or more commonly a combination of them. In addition, local factors such as adverse oral habits, anomalies in number, form and developmental position of teeth can also cause malocclusion. ${ }^{2}$ Early interception and early correction of these malocclusions will prevent their progression to its full form and will exclude factors interfering with the regular development of the dental arches. ${ }^{3}$

Now the World Health Organization estimates malocclusions as the third most prevalent oral health problem, following dental caries and periodontal diseases. ${ }^{4}$

The need for early detection and treatment of malocclusion is highlighted by its role in the development of periodontitis, dental caries, temporo-mandibular disorders and trauma. Moreover, malocclusion adversely affects oral functions like mastication, swallowing and speech. ${ }^{5}$ Though reports suggest that malocclusion is the second most common dental disorder affecting schoolchildren, there is inadequate implementation of preventive oral healthcare programs. ${ }^{6}$

Numerous studies have been published regarding the prevalence of malocclusion in various populations. The results have shown wide variations. Differences in the age ranges of the populations studied, the number of subjects examined and differences in the registration methods are probably the most important factors explaining these variations. ${ }^{7}$ The aim of the study to evaluation of malocclusion in the children aged 8-12 years in the village in Zakigonj area.

\section{MATERIALS AND METHOD}

A cross sectional descriptive survey was conducted among rural area (374) school- age children of Sylhet Zakigonj Upazila in Bangladesh. A total of 374 children aged 08-12 year old was examined for Class I, Class II, Class III molar relationship, increased over jet, increased over bite, open bite, crowding, cross bite and spacing after obtaining the written consent from the students, legal guardians and school authorities. The inclusion criteria were 1) School- age children 08- to 12 year old in selected school irrespective of sex without the 
history of previous orthodontic treatment. 2) Participants with completely erupted first permanent molars. The exclusion criteria were 1) Unwillingness of participant's as well as their legal guardian in the study. 2) Mentally compromised participants and participants with craniofacial anomalies. Boys and Girls were equally distributed. The participants were selected by criterion random sampling method which fulfills the predetermined selective criteria. A prior notification and written consent form was sent to the head of the school for permission to carry out the study. A written assent form was given to the participant prior to commencement of study. A written consent form was given to the participant's legal guardian. Materials and instruments required: 1) Informed written assent and consent forms from study participants along with their legal guardians,2) Preformed Data collection sheet 3) Pens 4) Torch light 5) Disposable diagnostic materials (calibrated probe, mirror) 6) Mask and 7) Gloves. The study sample along with their guardians were requested to give their agreement to participate in the study. The teacher was given a brief introduction about the investigator to the children. The investigators were addressing any concern or clarification that the students may require before carrying out the data collection. Their data was collected by the dental Health checkup. The oral health education lecture was given to all the children in the school to create awareness about dental health and Orthodontic treatment. After taking informed written consent from the guardians of study participants, assent from the minors and approval from ethical committee of BSMMU, school children was examined in ordinary chair using torch light and disposable diagnostic tools (periodontal probe, mirror, measurement scale). Study models and radiograph was not taken. Class I, Class II and Class III molar relationship and various traits of malocclusion was recorded by using Angle's classification. Over jet was measured by periodontal pocket measuring calibrated probe. It was increased when the horizontal space between upper and lower incisors are more than 3 $\mathrm{mm}$ or normal. The normal value of overbite is 1 to $3 \mathrm{~mm}$ but it varies with the length of incisors. When space remains between upper and lower teeth in centric occlusion then open bite was noted. Crossbite was recorded when there are an abnormal labiolingual or buccolingual relationship of the upper and lower teeth when the mouth was closed in normal occlusal position. Crowding was noted when there was overlying of two or more teeth or minimum $2 \mathrm{~mm}$ space lack in each quadrant. Spacing was collected when diastema was present between two nearby teeth or extra space of at least $2 \mathrm{~mm}$ was existing in each quadrant.

\section{Ethical considerations:}

Prior to the commencement of this study, ethical approval by the Institutional Review Board (IRB) of BSMMU was taken. The study was maintaining all the ethical principles in all procedures according to the declaration of Helsinki. The aim and objectives of the study 
along with its procedure, risks and benefits was explained to the participants an essay understandable local language. Data was collected maintaining confidentiality and privacy of the participants strictly. It was assured that all information and records was kept confidentially and the procedure was helpful for both the clinician and the participants in making rational approach of the case management. All participants were having a case number to maintain their confidentiality; all date was represented by their case number, not by their name or any other personal information that may leak their confidentiality. A written and signed informed consent was obtained from all participants. The written informed consent was containing the study name, type of study, risk and benefit of the participants, confidentiality and their right to withdraw from the research. The informed consent was taken from the participants with their legal guardians who also was sign on the consent form. This study was not involve any drugs, placebo, records (hospital, medical, birth, death or other), organs, tissues, body fluids, the fetus or the aborts. The participants were not getting any financial benefit.

\section{Statistical Analysis}

A data base was prepared and statistical analyses were carried out by using the Statistical Package for Social Sciences (SPSS Statistics for Windows, Version 23.0. Armonk, NY: IBM Corp. 2015). Continuous data were expressed as mean \pm standard deviation (SD) and categorical data were expressed as frequency and percentages. Mean and standard deviation were computed for quantitative variables and was analyzed by unpaired "t" test. Chi square test was used for categorical variables. $\mathrm{P}$ values $<0.05$ was considered as statistically significant.

\section{RESULTS AND DISCUSSION}

Total 374 patients come from rural area among them 247 patients belonged to age <10 years and 127 age $>10$ years. Figure 1 shows that majority 173(70.0\%) patients were found malocclusion in age $<10$ years and $89(70.1 \%$ ) in age $>10$ years. The difference was not statistically significant $(\mathrm{p}=0.994)$ between two groups. Figure 2 shows that majority $121(69.9 \%)$ participants were found Angle's class I in age $<10$ years and 75(84.3\%) in age $>10$ years. The difference was statistically significant $(\mathrm{p}=0.001)$ between two groups. Table 1 show that $137(79.2 \%)$ patients were found increased overbite of malocclusion in age $<10$ years and 60(67.4\%) in age $>10$ years group. One hundred six $(61.3 \%)$ patients were found crowding of malocclusion in age $<10$ years and 67(75.3\%) in age $>10$ years group. Which were not statistically significant $(\mathrm{p}<0.05)$ but increased overjet, open bite, cross bite and spacing were not statistically significant $(\mathrm{p}>0.05)$ between two groups. 


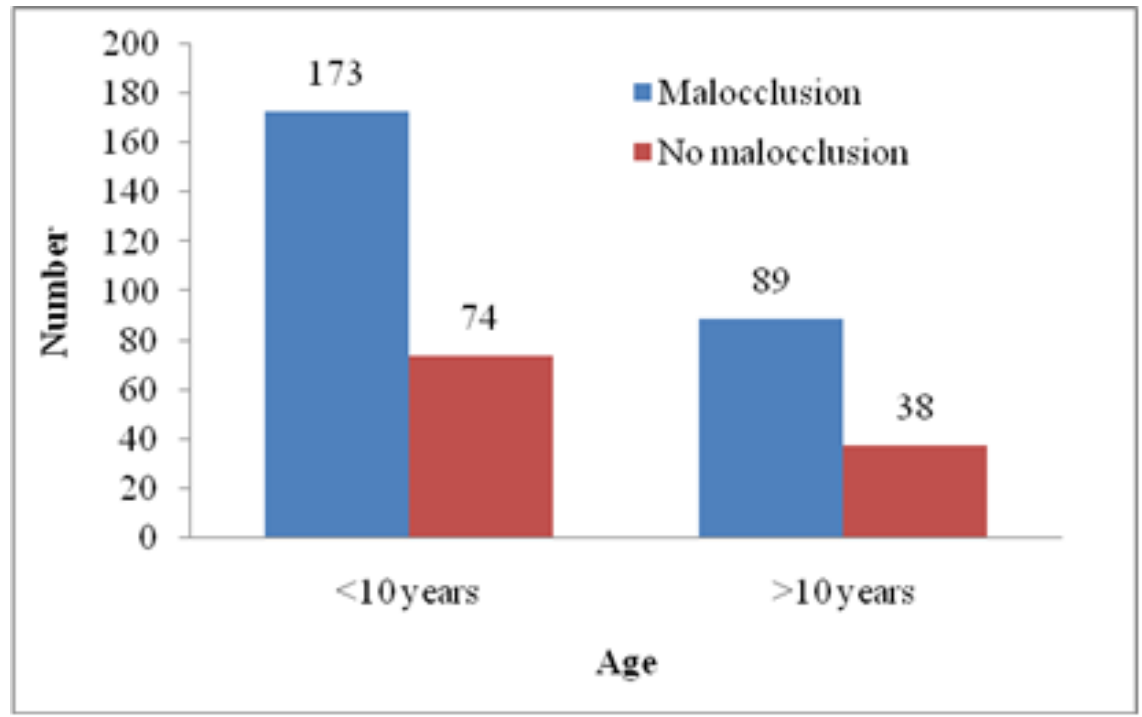

Figure 1: Association between malocclusion with age in rural area in Zakigonj

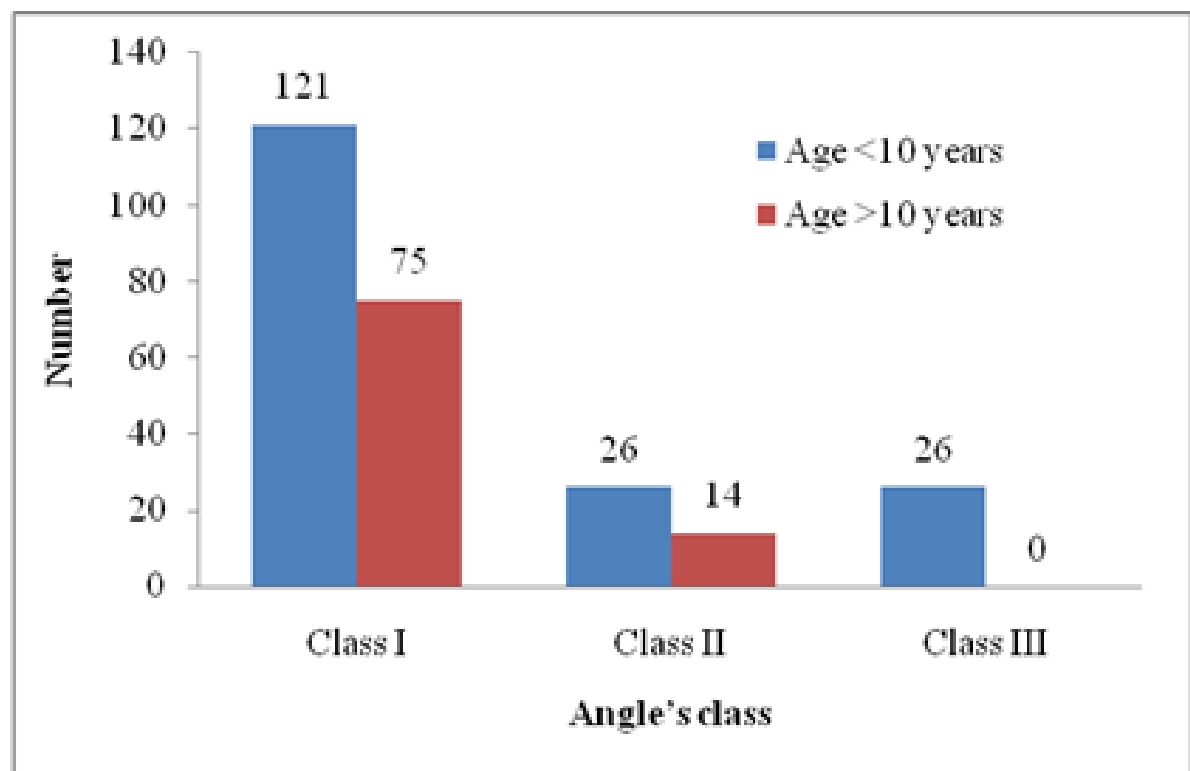

Figure 2: Distribution of Angle's class with age in rural area in Zakigonj

Table 1: Association between different variables of malocclusion with age in rural area of Zakigonj

\begin{tabular}{lllll}
\hline \multicolumn{2}{l}{ Type of malocclusion Total Age } & p value \\
& \multicolumn{4}{c}{ <10 years $(\mathbf{n = 1 7 3 )}) \mathbf{1 0}$ years $(\mathbf{n = 8 9 )}$} \\
\hline Increased overjet & 50 & $34(19.7)$ & $16(18.0)$ & 0.744 \\
Increased overbite & 197 & $137(79.2)$ & $60(67.4)$ & 0.037 \\
Open bite & 16 & $11(6.4)$ & $5(5.6)$ & 0.813 \\
Cross bite & 20 & $12(6.9)$ & $8(9.0)$ & 0.554 \\
Crowding & 173 & $106(61.3)$ & $67(75.3)$ & 0.023 \\
Spacing & 56 & $36(20.8)$ & $20(22.5)$ & 0.756 \\
\hline
\end{tabular}




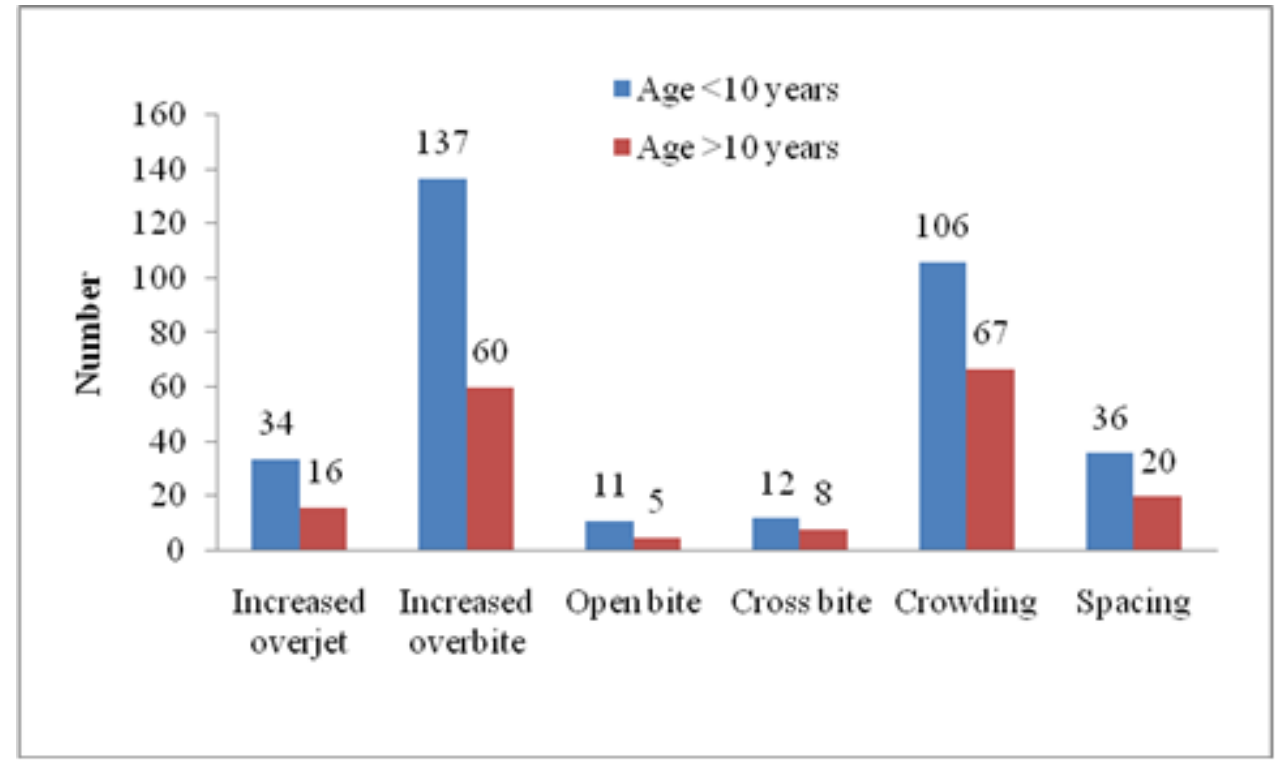

Figure 3: Association between different variables of malocclusion with age in rural area of Zakigonj

A cross sectional descriptive survey was conducted among rural area (374) school- age children of Sylhet Zakigonj Upazila in Bangladesh. Total 374 patients come from rural area among them 247 patients belonged to age <10 years and 127 age $>10$ years. In this study observed that majority $173(70.0 \%)$ patients were found malocclusion in age $<10$ years and $89(70.1 \%)$ in age $>10$ years. The difference was not statistically significant $(\mathrm{p}=0.994)$ between two groups. Balachandran et al. ${ }^{3}$ reported Participants of 13 years age group had a comparatively higher prevalence of malocclusion (33.50\%, CI: 33.34-33.66, 11 studies, 3366 participants) than other age groups. The increase in the prevalence of malocclusion by 13-14 years followed by its decline in 15 years can be understood by Knutson's explanation that these are age related correction of temporary malocclusion when the child outgrows deforming habits. ${ }^{4}$ Boeck et al. $^{8}$ reported majority $(79.19 \%)$ patients were found malocclusion in age 5-8 years and $82.52 \%$ in age 9-12 years. According to the statistical chisquare test, the prevalence of malocclusion showed no statistically significant difference in relation to gender, but there was a significant difference when comparing the two age groups in the sample.

In this study showed that majority 121(69.9\%) participants were found Angle's class I in age $<10$ years and $75(84.3 \%)$ in age $>10$ years. The difference was statistically significant $(\mathrm{p}=0.001)$ between two groups. Mehta et al. ${ }^{1}$ reported class I malocclusion was most common affecting more than half of the children $(51.3 \%$. CI 36.2, 66.3). Class II malocclusion affected $10.2 \%$ (CI 6.3, 14.9) and just $2.2 \%(0.8,4.2)$ children had class III malocclusion. Boys had higher proportion of class I and III whereas class II malocclusion was more prevalent in girls. Boys reported higher overall prevalence than girls. Class I malocclusion was most common affecting more than half of the children $(51.3 \%$. CI $36.2,66.3)$. Reddy et al. ${ }^{9}$ compared the 
incidence of pseudo class III between boys and girls of different age group. Out of 127 $(5.95 \%)$ children having pseudo class III, higher prevalence was seen in 7 year old $(16.07 \%)$ girls and 8 year old $\left(7.3 \%\right.$ ) boys. Boeck et al. ${ }^{8}$ also reported $60.24 \%$ participants were found Angle's class I in age 5-8 years and 69.47\% in age 9-12 years. Mostly, the three classes of Angle were more prevalent in the age group 2, when compared to age group one, as the malocclusion index in said group (nine to 12 years old) was significantly higher.

In present study showed that $137(79.2 \%)$ patients were found increased overbite of malocclusion in age $<10$ years and $60(67.4 \%)$ in age $>10$ years group. One hundred six (61.3\%) patients were found crowding of malocclusion in age <10 years and 67(75.3\%) in age $>10$ years group. Which were not statistically significant $(\mathrm{p}<0.05)$ but increased overjet, open bite, cross bite and spacing were not statistically significant ( $p>0.05)$ between two groups. Reddy et al. $^{9}$ reported Lower anterior crowding was detected in 252 (11.8\%) children with greater incidence in 9 year old (13.4\%) boys and 8 year old (20.5\%) girls. The occurrence of open bite was noticed in a total of $64(3 \%)$ children, with significance in 9 year old $(4.6 \%)$ boys and 8 year old $(7.07 \%)$ girls. Narayanan et al. ${ }^{2}$ revealed that deep bite (35.6\%) was the most prevalent, followed by increased overjet $(23.2 \%)$ and crossbite $(7.2 \%)$. The least noted characteristics were open bite $(0.29 \%)$ and midline diastema $(0.76 \%)$. overjet less than $3 \mathrm{~mm}$ was categorized as normal and it was found that $23.2 \%$ of the subjects were with increased overjet, which is similar to the findings of Abu Alhaija et al ${ }^{10}$ in Jordan (24.7\%) and Gelgor et $\mathrm{al}^{11}$ in Central Anatolia (25.1\%). The studies by Farahani et $\mathrm{al}^{12}$ in Iran (31.7\%) and Hemapriya et $\mathrm{al}^{13}$ in Kancheepuram, India (61.4\%) reported a higher prevalence of increased overjet, while lower prevalence was reported in the studies by Siddegowda and $\mathrm{Rani}^{14}$ in Karnataka $(6.3 \%)$, India and Poeung et $\mathrm{al}^{15}$ in Cambodia $(8.1 \%)$.

\section{CONCLUSION:}

The results suggested that there is increased prevalence of malocclusion among children in the 8-12 years age group. The observation of this study will provide baseline data for implement early interceptive treatment for the elimination of factors inhibiting dental arch development as well as skeletal jaw growth.

\section{REFERENCE}

1. Mehta A, Negi A, Verma A, Jain K. Pooled prevalence estimates of malocclusion among Indian children and adolescents: a systematic review and meta-analysis. International Journal of Adolescent Medicine and Health. 2020 Aug 24:1-9 PMID: 32829315 DOI: 10.1515/ijamh-2020-0142 
2. Narayanan RK, Jeseem MT, Kumar TA. Prevalence of malocclusion among 10-12year-old schoolchildren in Kozhikode District, Kerala: An epidemiological study. International journal of clinical pediatric dentistry. 2016 Jan;9(1):50. PMID: 27274156 PMCID: PMC4890063 DOI: 10.5005/jp-journals-10005-1333

3. Balachandran P, Janakiram C. Prevalence of malocclusion among 8-15 years old children, India-A systematic review and meta-analysis. Journal of Oral Biology and Craniofacial Research. 2021 Jan 23. https://doi.org/10.1016/j.jobcr.2021.01.011

4. Sanadhya S, Chadha M, Chaturvedi MK, Chaudhary M, Lerra S, Meena MK, Bakutra G, Acharya S, Pandey A, Tak M, Asawa K. Prevalence of malocclusion and orthodontic treatment needs among 12-15-year-old schoolchildren of fishermen of Kutch coast, Gujarat, India. International maritime health. 2014;65(3):106-13. PMID: 25471158 DOI: 10.5603/IMH.2014.0023

5. Guo L, Feng Y, Guo HG, Liu BW, Zhang Y. Consequences of orthodontic treatment in malocclusion patients: clinical and microbial effects in adults and children. BMC Oral Health. 2016 Oct 28;16(1):112. PMID: 27793138 PMCID: PMC5084385 DOI: $10.1186 / \mathrm{s} 12903-016-0308-7$

6. Agarwal SS, Jayan B, Chopra SS. An overview of malocclusion in India. J Dent Health Oral Disord Ther. 2015 Dec;3(3):1-4. DOI: 10.15406/jdhodt.2015.03.00092

7. Agarwal SS, Chopra SS, Jayan B, Verma M. Epidemiology in orthodontics a literature review. Orthod Cyber J 2013 Sep.

8. Boeck EM, Pizzol KE, Navarro N, Chiozzini NM, Foschini AL. Prevalence of malocclusion in children between 5 and 12 years-old in municipal schools in Araraquara. Revista CEFAC, 2013; 15:1270-80. DOI:10.1590/S151618462012005000090

9. Reddy ER, Manjula M, Sreelakshmi N, Rani ST, Aduri R, Patil BD. Prevalence of Malocclusion among 6 to 10 Year old Nalgonda School Children. J Int Oral Health 2013; 5(6):49-54. PMCID: PMC3895717,PMID: 24453444

10. Abu Alhaija ES, Al-Khateeb SN, Al-Nimri KS. Prevalence of malocclusion in 13-15 year-old North Jordanian school children. Community Dent Health 2005 Dec;22(4):266-271. PMID: 16379166

11. Gelgor IE, Karaman AI, Ercan ER. Prevalence of malocclusion among adolescents in Central Anatolia. Eur J Dent 2007 Jul;1(3): 125-131. PMID: 19212555 PMCID: PMC2638238

12. Farahani AB, Farahani AB, Eslamipour F. Malocclusion and occlusal traits in an urban Iranian population. An epidemio- logical study of 11- to 14-year-old children. Eur J Orthod 2009 Oct;31(5):477-484. PMID: 19477970 DOI: 10.1093/ejo/cjp031 
13. Hemapriya S, Ingle NA, Chaly PE, Reddy VC. Prevalence of malocclusion and orthodontic treatment needs among 12 and 15 years old rural school children in Kancheepuram district. J Oral Health Community Dent 2013 May; 7(2):84-90. DOI:10.5005/johcd-7-2-84

14. Siddegowda R, Rani MS. A cross-sectional epidemiological survey on prevalence of malocclusion in government, aided and private school children of Karnataka. Univ $\mathbf{J}$ Public Health 2013;1(3):124-130. DOI: 10.13189/ujph.2013.010312

15. Poeung P, Kruger E, Tennant M. The prevalence of malocclusion, dental irregularities and orthodontic treatment need in 13-15 year olds in Teuk Klaing, Cambodia. J Int Oral Health 2011 Oct;3(5):19-28

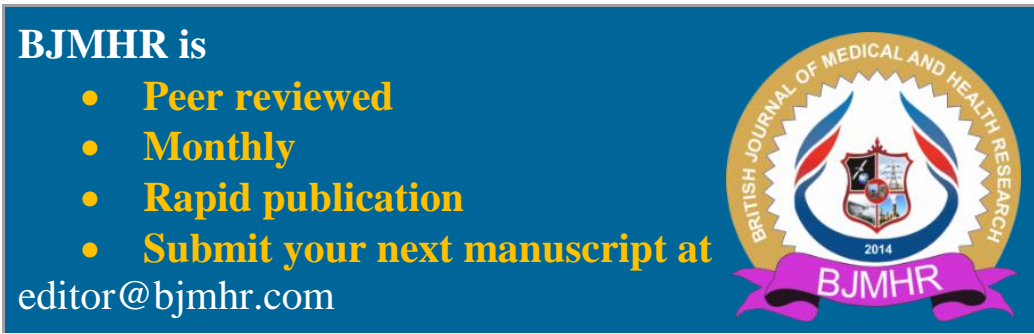

